\title{
"Frankenweenie": um olhar para o meio fílmico e o ensino de ciências
}

Kathya Rogéria da Silva kathyarsilva@gmail,com Universidade Estadual do Oeste do Paraná (Unioeste), Cascavel, Paraná, Brasil

Marcia Borin da Cunha marciaborin.unioeste@gmail.com Universidade Estadual do Oeste do Paraná (Unioeste), Cascavel, Paraná, Brasil

\section{RESUMO}

O cinema é uma mídia que faz parte do cotidiano dos estudantes, seja pelo hábito de ir ao cinema ou de assistir filmes em casa. No ambiente escolar, o cinema tem diferentes potencialidades, podendo ser um instrumento de discussão, de investigação ou para o desenvolvimento de atividades relacionadas aos conceitos tratados em sala de aula. Por isso, é necessário olhar para o filme de modo a compreender a dimensão estética, a ideologia e os valores socioculturais presentes no meio fílmico. Nessa perspectiva, o filme de animação "Frankenweenie", lançado no ano de 2012, foi assistido, descrito e analisado, abordando amplos e detalhados aspectos do filme, que podem ser discutidos durante as aulas de Ciências, apresentando uma descrição da imagem de Ciência e cientistas presentes neste filme, a fim de instruir ou orientar professores durante o trabalho com filmes em sala de aula. A partir disso, observamos que o cientista representado é Victor, um menino que nasceu com aptidões voltadas para Ciência, pois tem muita habilidade intelectual na disciplina de Ciências e para o manuseio de diferentes equipamentos. Ao ver seu cão e melhor amigo morrer, decide utilizar os conhecimentos aprendidos nas aulas de Ciências, para reviver o seu animal. O filme traz diferentes aspectos da pesquisa científica, como a competição e as variáveis envolvidas no processo. Entretanto, apresenta a ciência basicamente como experimental, pois durante todo o enredo, a pesquisa de Victor e de seus colegas está sempre relacionada a comprovações experimentais.

PALAVRAS-CHAVE: Ensino de Ciências. Cinema. Imagem de Ciência. 


\section{INTRODUÇÃO}

A escola deve ser entendida como um ambiente formador de cidadãos que sejam capazes de compreender as mídias de forma geral. As mídias já fazem parte do cotidiano dos estudantes e, quando são incorporadas nas aulas auxiliam na formação sociocultural. A utilização em sala de aula de imagens, animações, jornais, revistas, cinema, entre outros faz com que o acesso seja democrático e, como consequência, a escola torna-se responsável por alfabetizar a criança para ser um cidadão livre e consciente de suas escolhas midiáticas, isto é, uma criança ou adolescente crítico capaz de conhecer e de decidir quais mídias irá consumir.

Uma das mídias a ser considerada no ambiente escolar é o cinema, que apresenta grande potencialidade como objeto de estudo no âmbito educacional. Os filmes aos poucos têm sido reconhecidos como uma fonte de investigação de problemas de interesse educacional. Estes precisam ser encarados no âmbito pedagógico como uma obra de arte e, ao mesmo tempo, um instrumento pedagógico de grande valia para desenvolver aspectos relativos a valores, crenças e ideologias.

O cinema é um fenômeno moderno, que possui muitas facetas. Ao mesmo tempo em que é arte, também é indústria. É entretenimento e também é cultura. Possui caráter pedagógico ao mesmo tempo em que pode ser utilizado como veículo de propagação de determinadas visões ideológicas (SILVA, 2010, s/p.).

Por apresentar estas características próprias, o cinema cria vínculos com o espectador, fazendo com que desperte os mais variados interesses, pois a partir dos filmes são contadas histórias capazes de interpelar o espectador por meio do prazer, sonho e imaginação. As cenas transmitidas "[...] mexem com nosso inconsciente, embaralham as fronteiras do que entendemos por realidade e ficção. Quando dizemos que o cinema cria um mundo ficcional, precisamos entendê-lo como uma forma de a realidade apresentar-se" (FABRIS, 2008, p. 118).

Não tem como negar a influência causada pela tela do cinema na vida das pessoas, isso porque ele é capaz de exibir representações e significações que as pessoas podem e criam a respeito de suas próprias vidas. A ficção e a imaginação afloram quando uma pessoa fica à frente da "telona" para apreciar uma projeção cinematográfica, sendo que as imagens envolvem sentidos e de subjetividades que poderão ser mais ou menos percebidas dependendo dos espectadores. As imagens, assim como a educação visual contemporânea, auxiliam de forma estética e política a construírem e reconstruírem a relação do homem com ele mesmo e do homem com a sociedade (ANDRADE, 2000).

Duarte (2002), destaca que:

[...] o cinema está no universo escolar, seja porque ver filmes (na telona ou na telinha) é uma prática usual em quase todas as camadas sociais da sociedade, seja porque se ampliou, nos meios educacionais, reconhecimento de que, em ambientes urbanos, o cinema desempenha um papel importante na formação cultural das pessoas (DUARTE, 2002, p. 86).

Pelo fato do meio fílmico estar presente no cotidiano das pessoas, ele possibilita um espaço de interação entre espectadores e cinema, promovendo uma 
ação educativa, seja no âmbito social, cultural ou intelectual. Os filmes podem ser considerados agentes de socialização, isto porque possibilita a interação de pessoas com culturas e conhecimento distintos.

Por isso, a inserção de mídias no âmbito escolar pressupõe mudanças no trabalho pedagógico e nas relações estabelecidas entre os sujeitos, porque ela é capaz de produzir relações, criar sentidos e significados para os sujeitos, promovendo a aprendizagem a partir de situações cotidianas que estão sendo veiculadas.

Na perspectiva de incluir novas metodologias em aulas tradicionais, sugere-se a utilização de filmes comerciais que, desde que corretamente utilizados podem ser considerados um recurso atrativo e agradável.

Entretanto, o uso instrumental do cinema na escola, isto é, a utilização de filmes como forma de contextualização ou de exemplificação, delimita e reduz o potencial do uso de filmes em sala de aula, pois abordam apenas conteúdos programáticos, deixando de lado aspectos relevantes, como a dimensão estética, a ideologia e o valor sociocultural da obra cinematográfica. Por isso, é preciso olhar para os filmes e não apenas através deles, para que eles não sejam apenas ilustrações dos conteúdos programáticos (DUARTE; ALEGRIA, 2008).

Filmes expressam o olhar não só das pessoas envolvidas em sua montagem, mas, indiretamente, revelam o imaginário de seus espectadores, pois antes mesmo de vir a contribuir na formação e reforço de hábitos culturais, a produção de um determinado filme leva em conta a visão do seu público alvo, seu universo de referências, conhecimentos e expectativas (OLIVEIRA, 2006, p. 141).

É importante que o espectador ao assistir a um filme pense e repense sobre as imagens que estão sendo veiculadas, quais as relações estabelecidas e principalmente, em qual contexto histórico e social essas representações foram produzidas. Quando a mídia cinematográfica passa a integrar o ambiente escolar é preciso considerar que o filme, por ser um produto sociocultural, transmite diferentes representações que podem ser entendidas de diferentes formas, pois depende do público que está assistindo.

Nessa perspectiva, apresentaremos aqui a análise do filme do gênero animação, Frankenweenie, lançado no ano de 2012. Nessa análise, buscamos identificar as representações de Ciência e cientistas presentes no meio fílmico. Serão levados em consideração ainda, as inspirações utilizadas pelo diretor do filme para o compor e, as características predominantes do mesmo.

A escolha do filme Frankenweenie está relacionada ao seu enredo, isto é, por ele ser uma releitura de um filme considerado clássico do cinema, Frankenstein. 0 primeiro filme sobre Frankenstein foi lançado em 1910 por Edison Studios, escrito e dirigido por J. Searle Dawley. 


\section{METODOLOGIA}

O filme escolhido foi Frankenweenie e, que foi inicialmente assistido, a fim de conhecer os aspectos centrais do filme. Conhecendo o enredo e os personagens principais do filme, ele foi novamente assistido e sua análise foi iniciada seguindo a metodologia de Vanoye (2008, p. 15) que considera que analisar um filme consiste em "[...] despedaçar, descosturar, desunir, extrair, separar, destacar e denominar materiais que não se percebem isoladamente 'a olho nu', uma vez que o filme é tomado pela totalidade". Nessa análise, o filme foi assistido diversas vezes e as cenas foram descritas levando em consideração diferentes aspectos, como: a posição da câmera; construção dos personagens e das cenas; fala dos personagens (sendo que algumas foram transcritas); contexto no qual enredo acontece, entre outros.

Após essa descrição inicial, as cenas foram olhadas separadamente, observando as potencialidades e a relevância com a pesquisa, que visa analisar as possíveis formas de utilização do meio fílmico no ensino de Ciências. Posteriormente, as cenas foram unidas, formando uma totalidade, a qual possibilita a compreensão do filme como um todo, considerando todos os aspectos que o envolvem, incluindo a montagem, a direção, incluindo outras análises já realizadas com focos diferentes desse filme.

Desta forma, essa análise tem como objetivo observar as principais possibilidades do filme para o contexto educacional, isto é, serão abordados amplos e detalhados aspectos do filme que pode ser discutidos por professores nas aulas de Ciências, possibilitando observar em quais níveis de ensino esse filme pode ser utilizado.

\section{RESULTADOS}

O filme Frankenweenie (2012) é uma adaptação de um curta-metragem produzido em live-action (termo que significa a combinação de atores reais e elementos criados por meio de animações que interagem durante o filme), sob o mesmo título em 1984 e dirigido por Tim Burton. Entretanto, a distribuidora The Walt Disney Studios considerou a história e o formato impróprios para o público infantil, sendo, portanto, arquivado. Esse curta tinha duração de vinte e nove minutos e era baseado no filme Frankenstein de 1931, dirigido por James Whale. Apenas em 2007, Tim Burton voltou a The Walt Disney Studios e refez sua ideia original, o transformando em um longa-metragem 3D e stop motion (é uma técnica que utiliza a disposição sequencial de fotografias diferentes de um mesmo objeto inanimado para simular o seu movimento) (FÜHR, 2016b).

No quadro 1 apresentamos a ficha técnica do filme. 
Quadro 1 - Ficha Técnica do filme

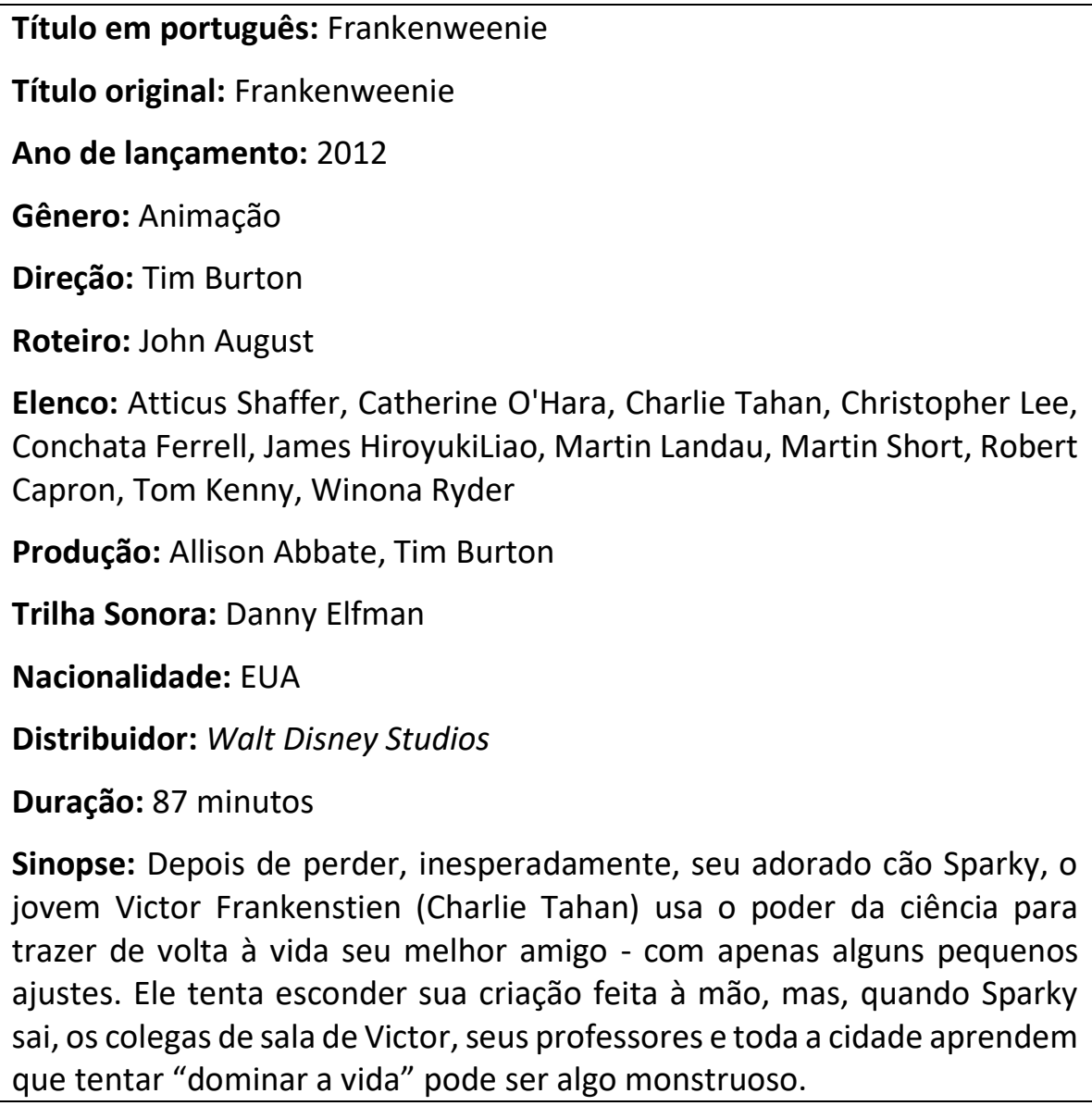
jovem Victor Frankenstien (Charlie Tahan) usa o poder da ciência para trazer de volta à vida seu melhor amigo - com apenas alguns pequenos ajustes. Ele tenta esconder sua criação feita à mão, mas, quando Sparky sai, os colegas de sala de Victor, seus professores e toda a cidade aprendem que tentar "dominar a vida" pode ser algo monstruoso.

Fonte: <https://www.cineclick.com.br/frankenweenie>. Acesso em: mai. 2017.

A ideia de fazer o filme, surgiu quando Tim Burton reassistiu ao filme de Frankenstein e lembrou de um cão vira lata, de cor branca que teve na infância e morreu de cinomose (doença causada por um vírus que sobrevive em ambiente seco e frio). A partir disso, ele imaginou como seria poder trazer um ser de volta a vida. Entretanto, ele percebeu que todas as adaptações feitas até então traziam apenas o lado negativo e, por isso tentou fazer algo diferente. Essa nova versão de Frankenstein traz uma visão mais otimista pois, ao invés de criar um monstro, o Victor de Tim Burton devolve à vida ao seu melhor amigo: seu cachorro Sparky (MAYO, 2012).

Além disso, Tim Burton é um fã de filmes de terror e fazia suas próprias criações desde criança em super-8 (também chamado de Super $8 \mathrm{~mm}$ é um formato cinematográfico desenvolvido na década de 1960, como um aperfeiçoamento do antigo formato $8 \mathrm{~mm}$, que mantinha a mesma bitola). Frankenweenie é mais um dos trabalhos autobiográficos do diretor, que também é o criador de filmes como Edward Mãos de Tesoura (1990) (distribuído pela Fox Film do Brasil), Noiva Cadáver (2005) (distribuído pela Warner Bros) e Sweeney Todd (2007) (distribuído pela Warner Bros).

Frankenweenie (2012) é uma adaptação fílmica na qual se identifica pontos 
Frankenweenie (2012), Tim Burton optou por narrar a história a sua própria maneira, assim apenas o argumento central do romance é mantido: "dar vida a matéria morta" (FÜHR, 2016a, p. 7).

A animação foi toda produzida em preto e branco. Para Tim Burton essa nuance de cores desempenha papel fundamental na animação, fazendo com que as cenas variem entre tons de preto, cinza e branco em algumas gradações. Essa escolha de cores faz parte de uma homenagem de Tim Burton aos filmes de horror e de ficção científica anteriores a década de 1960.

Outro fato importante sobre o filme é que alguns personagens foram baseados em outros personagens do cinema, que foram homenageados por Tim Burton, como é o caso de personagens com o próprio Victor Frankenstein. Elsa Van Helsing que tem o nome de um caçador de vampiros do filme Drácula, filme produzido pela Universal Studios e dirigido por Tod Browning, no ano de 1931. O personagem Edgar "E" Gore que lembra o Corcunda de Notre Dame, do livro de Victor Hugo (1831) e o personagem Nassor, inspirado em Frankenstein interpretado por Boris Karloff, no filme Frankenstein produzido pela Universal Studios e dirigido por James Whale, em 1931.

Podemos citar ainda, a homenagem a Mary Shelley (escritora do livro que inspirou o clássico cinematográfico Frankenstein), que aparece simplesmente como Shelley, a tartaruga de Toshiaki e o ator Chistopher Lee, que aparece em uma das cenas como Drácula, durante a exibição do filme na televisão da família e, o professor de Ciências, o Sr. Rzykruski é muito semelhante ao ator Vicent Price.

Outra característica marcante nos filmes de Tim Burton, inclusive na animação de Frankenweenie, é a presença do Expressionismo Alemão, que foi a base para a cinematográfica Expressionista e, está relacionado a produção de filmes com "[...] cenários bizarros, sombras exageradas e iluminação com alto contraste" (FÜHR, 2016b, p. 99). O Expressionismo busca representar o mundo por meio de deformações, mostrando o mundo interno de forma conflituosa com o sujeito, que está em conflito com aquilo que ele busca.

A deformação pode ser vista na caracterização dos personagens, que é exagerada e traz traços marcantes e que são capazes de descrever os personagens. Essas imagens deformadas e distorcidas presentes nessa animação, causam, muitas vezes, mal-estar na sociedade, pois a estabilidade pode ser obtida por meio dos significados dadas como naturais no imaginário social (ROURE; SÁ, 2014).

A caracterização dos personagens é importante na construção dessa animação, pois são perceptíveis as ambiguidades e as características pessoais de cada personagem que compõem a trama. Isso é possível por meio da forma com que o personagem se expressa, seja por expressões faciais exageradas - nítidas nessa animação - seja pela maneira de falar, andar e de se comunicar com os demais personagens. A união dessas características é que compõem os personagens e, que os tornam únicos e podem ser diferenciados dos demais.

Como é o caso da personagem Menina Esquisita (nome da personagem), que foi caracterizada com olhos arregalados, fala mansa e calma, mesmo em situações de perigo, cabelos trançados, usando vestido. Essas características juntamente 
com o figurino compõem a personagem e fazem o espectador compreender a função do personagem no filme.

A escolha dos figurinos dos personagens possibilita, por meio da percepção visual, compreender o contexto histórico no qual o filme foi ambientado, algumas características inerentes do personagem, como sexo, idade, aparência e peculiaridades de cada personagem. Isso é possível perceber em todos os personagens da animação, como o fato da mãe de Victor aparecer na maioria das vezes com um avental, remete a ela os cuidados do filho e da casa.

A vestimenta do professor Sr. Rzykruski sempre de terno, que mantém a postura e a superioridade em relação aos seus alunos. E o próprio Victor que se apresenta como um menino "comum", que quando vai realizar o seu experimento utiliza os trajes de segurança necessários em um laboratório, como luvas, jaleco e até mesmo óculos de proteção (Figura 1).

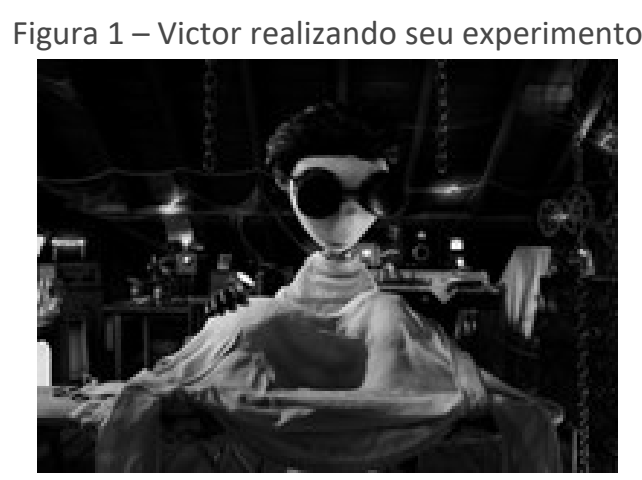

Fonte: <http://www.papodecinema.com.br/filmes/frankenweenie>. Acesso: mai. 2017.

A forma como essas diferentes caracterizações foram realizadas podem ser discutidas durante as aulas de Ciências, seja levando-se em consideração a tecnologia necessária para o aperfeiçoamento dos personagens, destacando a maneira como os personagens são projetados, seja considerando essas representações essenciais para a compreensão da função do personagem no enredo fílmico ou em determinada cena.

O conflito está muito presente nessa animação, afinal Victor realiza seu experimento trazendo de volta seu melhor amigo. Ele entra em conflito pessoal e também com os demais personagens pelo seu ato, esse conflito pode ser visto quando seu pai Edward o questiona afirmando que o menino ultrapassou os limites entre a vida e a morte.

As cenas do filme Frankenweenie (2012) tem como plano de fundo uma história presente nos clássicos de terror, isso é mostrado de forma sutil no filme, por meio do cenário e também pela estética dos personagens.

Os principais cenários do filme são a casa da família Frankenstein e sua vizinhança, como a casa de Sr. Burgemeister, a escola de New Holland Elementary e a cidade de New Holland em si, que funciona como um plano de fundo para o enredo. 
A casa dos Frankenstein pode ser descrita como uma típica casa de uma família de classe média, as cercas são baixas, assim como de toda a vizinhança. A casa é acoplada com vários eletrodomésticos que são usados tanto por Susan quanto por Victor. A casa conta ainda com um sótão (Figura 2), o qual Victor o usa como laboratório. Esse espaço é grande, Victor tem uma mesa grande, um quadro, um balanço antigo e vários equipamentos oriundos de outras partes da casa, como ferramentas e equipamentos eletrodomésticos.

Figura 2 - Victor no sótão de sua casa

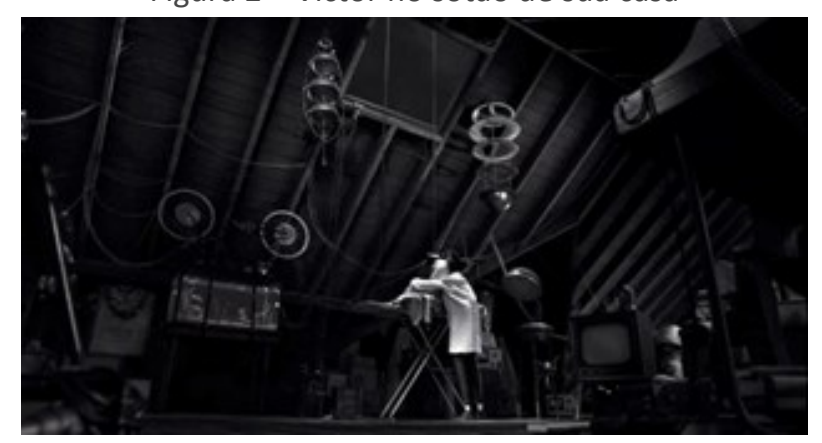

Fonte: $<$ http://www.globeslcc.com/2012/10/08/frankenweenie-is-a-fine-tribute-tohorror-films-and-a-return-to-burtons-roots/>. Acesso em: mai. 2017.

O laboratório de Victor aparece nas principais cenas que envolvem Ciência no filme. Ele é um espaço amplo e improvisado, caracterizado pelos objetos que nele contêm, como eletrodomésticos e eletroeletrônicos domiciliares. O fato do laboratório ser na residência de Victor remete a ideia de que a Ciência exerce forte influência na vida do personagem. A imagem do laboratório deve ser amplamente discutida durante as aulas de Ciência, a fim de que o estereótipo de que a pesquisa científica ocorre apenas em grandes laboratórios seja desmistificado e, os estudantes compreendam a função de um laboratório na pesquisa científica.

A escola da cidade é de médio porte e as imagens ficam restritas à sala de aula da turma de Victor e à fachada onde ocorrem diálogos importantes de Victor com alguns personagens, como por exemplo, com o professor de Ciências após a realização dos dois experimentos.

A sala de aula é um grande espaço, com janelas amplas, as carteiras são distribuídas em filas, como em uma escola tradicional. Ainda, o professor conta com uma bancada como de laboratório, fazendo com que a sala adquira outras funções, isto é, durante uma das cenas, o processo demonstra a eletricidade em uma rã na própria sala de aula. Essa ainda é equipada com um extintor de incêndio e várias vidrarias e equipamentos laboratoriais, como béqueres, erlenmeyers, microscópios, entre outros.

A explicação do resultado desse experimento é pouco discutida no enredo fílmico, desta forma, é possível a realização do mesmo em ambiente escolar e a partir dele levantar hipóteses sobre a utilização da eletricidade no mesmo. Além disso, pode-se considerar uma abordagem sobre a temática eletricidade, suas aplicações no cotidiano e promover uma discussão acerca do experimento de 
A cidade é mostrada em algumas cenas, nas quais é possível visualizar o moinho de vento ao fundo, que é discutido nas primeiras cenas em sala de aula pelos alunos. Podendo ser vistas cenas do Dia Holandês, uma importante festa para a movimentação da cidade e também para o prefeito, o Sr. Burgemeister.

Os personagens foram produzidos a partir da construção de bonecos. 0 primeiro boneco construído foi de Sparky, pois Tim Burton gostaria que o boneco se mexesse e tivesse ações como de um animal de verdade. O boneco de Sparky mede 10 centímetros e foram construídos um total de doze bonecos idênticos do animal. A partir da construção do cachorro, foram feitos os demais bonecos do filme, totalizando duzentos bonecos, sendo dezessete bonecos Victor. Essa quantidade de bonecos se deve ao fato de muitas vezes, várias cenas eram feitas ao mesmo tempo e os personagens poderiam sofrer escoriações durante as filmagens, sendo preciso dublês para assumirem as cenas. Todos foram confeccionados em silicone e látex (KÜCHLER, 2012).

A narrativa traz a história de Victor Frankenstein, que é filho único de Edward e Susan Frankenstein. Ele é um garoto solitário que tem apenas um amigo, Sparky o cachorro da família.

O filme mostra Victor como um menino extremamente inteligente que possui aptidões para a Ciência, como na cena em que Edgar o procura para fazer dupla com ele, acreditando que quem fizer com Victor irá ganhar o prêmio da Feira de Ciências. Ainda nessa cena, Victor diz a Edgar que prefere trabalhar sozinho, caracterizando seu isolamento perante aos colegas de classe.

Victor apresenta uma caracterização científica oriunda da mídia, na qual o cientista além de uma aptidão nata para a Ciência, é uma pessoa pouco sociável e que está sempre com vestimentas apropriadas para o trabalho no laboratório. A veiculação desta imagem potencializa a ideia de que a Ciência é para poucos, ou ainda que ela é realizada apenas em grandes laboratórios. Para desmistificar ou diminuir essa ideia, é possível que algumas cenas do filme sejam discutidas em sala de aula, com o objetivo de discutir e possibilitar que os estudantes realizem reflexões a respeito da profissão de cientista.

O pai de Victor teme que o menino seja visto como estranho, pelo fato de não ter amigos e não realizar atividades corriqueiras para meninos de sua idade e, por isso, decide fazer uma pequena chantagem com ele, ou seja, Victor deverá jogar beisebol para poder participar da Feira de Ciências. Mesmo sem Victor demonstrar interesse na atividade, ele a realiza para a satisfação do pai, mas principalmente com um único intuito poder concorrer ao prêmio da Feira de Ciências, almejando mais do que prêmio e, sim o reconhecimento por um experimento até então não decidido por Victor.

Apesar de ser um menino quieto e introspectivo, Victor gosta de mostrar seus feitos científicos, principalmente para os pais. Na primeira cena do filme, Victor apresenta para os pais um filme produzido por ele, a fim de demonstrar suas aptidões para a Ciência. O filme foi produzido e filmado por ele (Victor) e utiliza da técnica 3D. O personagem principal de seu filme é Sparky, que enfrenta uma luta contra monstros, que estão invadindo a cidade. Além do filme, Victor é quem organiza e produz o projetor para o filme. Ao final da apresentação do filme, ocorre 
um problema e a fita trava, deixando Victor desapontado e decepcionado, que se retira da sala a fim de consertar o quanto antes o problema.

No sótão, o menino encontra rapidamente a causa do problema e, seus pais na sala conversam sobre a falta de amigos do menino, que para o pai é um grande problema, enquanto a mãe ameniza, afinal Victor tem Sparky e, pode contar com ele para tudo. Essa cena faz com que o espectador compreenda que Victor possui um brilhantismo e, que tem múltiplas facetas, no que se refere ao conhecimento científico.

Na casa dos Frankenstein poucas são as cenas na qual ocorre um diálogo entre pais e filho, mesmo Victor sendo uma criança. Até mesmo quando Sparky morre, os pais respeitam o luto do menino e fazem perguntas com respostas curtas e simples, como "como foi sua aula hoje?". Também é preciso destacar que muitas vezes o menino não é visto pelos seus pais, como se não o acompanhassem. Isto é, na cena em que Victor entra com o corpo de Sparky em casa, seus pais estão assistindo a um filme e não percebem a ausência e nem a entrada do menino, que por mais cuidadoso que seja, ele ainda é uma criança e, deveria receber cuidados especiais dos pais.

Victor passa horas isolado no sótão de sua casa, que ele construiu o seu laboratório sem supervisão dos pais, sendo possível até mesmo esconder que reviveu o seu cachorro Sparky, que chega até a dormir no quarto de Victor durante uma noite. Além do sótão, o quarto de Victor também revela seu interesse pela área científica. Seu quarto tem como papel de parede vários planetas que ficam ao lado de sua cama.

O fato de Victor ser uma criança e reviver seu cachorro traz a narrativa sobre a temática Frankenstein, um ar menos sombrio e mais próximo do espectador. Desta forma, o cientista do filme não tem características comuns das representações mais comuns de Victor Frankenstein (filme origem), como um homem que extrapolou os limites da Ciência, alguém antiético e egoísta. O Victor Frankenstein de Tim Burton é um menino, que sentindo sozinho e, a partir do conhecimento adquirido durante as aulas de Ciências e seu brilhantismo, traz seu melhor amigo e cão à vida.

Outra característica é que a criatura de Frankenweenie continua com suas as características principais mantidas, pois ele continua sendo um cachorro fiel e amigável com seu dono, aparentemente apaixonado por Persephone (cachorra da vizinha de Victor), que com a qual tem encontros escondidos pelas frestas das cercas, brincalhão e cheio de energia.

O filme de Tim Burton mostra que o diferente, nesse caso específico, Sparky (Figura 3) após reviver é rejeitado a princípio, não sendo aceito nem pelas pessoas que conviveram com ele, como os pais de Victor e, posteriormente, pela população da cidade que o acusa de um crime que ele não cometeu. Contudo, conforme as cenas se desenrolam esse aspecto da não aceitação é esquecido, e ele volta a ser bem recebido dentro do contexto social, ao contrário das típicas criaturas do filme original de Frankestein promovidas pelo cinema, que sofrem com a rejeição não apenas do criador, como também da sociedade e sofrendo com isso até o seu destino final. 
Figura 3 - Victor e Sparky após o experimento

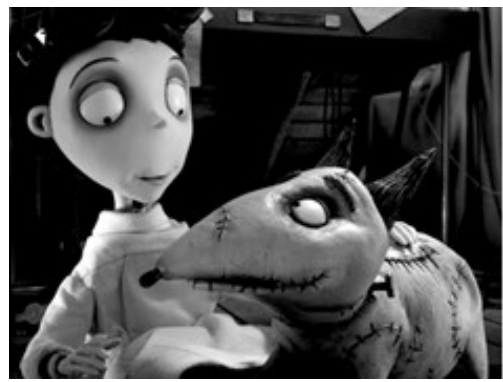

Fonte: <http://www.papodecinema.com.br/filmes/frankenweenie>. Acesso: mai. 2017.

O experimento de Victor somente é possível a partir das aulas de Ciências de Sr. Rzykruski. Aliás, o professor que é um coadjuvante na animação desempenha papel fundamental na realização do experimento e também em outra cena, em uma conversa com Victor.

O Sr. Rzykruski (Figura 4) é apresentado ao espectador logo que filme é ambientalizado na escola, nos primeiros dez minutos da trama. O professor é apresentado ao espectador em contra-plongée (enquadramento na qual a câmera filma o foco principal da cena de baixo para cima, deixando o espectador abaixo do personagem, ou objeto e engrandecendo-o na cena) ou simplesmente câmera baixa, com a intenção de conferir ao professor ar de superioridade em relação aos alunos, destacando que é ele é a figura que detém o conhecimento científico e que será capaz de ensinar os alunos. E para aumentar essa sensação, os alunos são apresentados em plongée, ou câmera baixa, isto é, como se o espectador fosse o professor observando os alunos, mantendo o olhar de superioridade (FÜHR, 2016b).

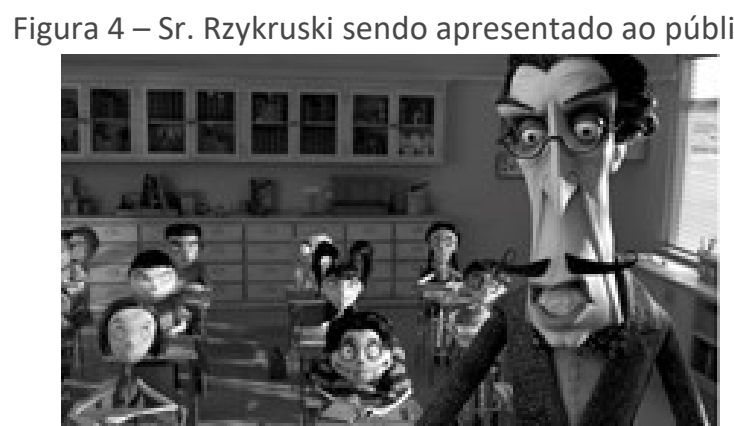

Fonte: <http://www.papodecinema.com.br/filmes/frankenweenie>. Acesso: mai. 2017.

É importante destacar que mesmo a câmera sendo posicionada desta forma, o professor com ar de superioridade, ouve os alunos durante suas aulas. Isso é perceptível já na primeira aula, na qual os alunos discutem e levam hipóteses sobre as possíveis causas da cidade de New Holland estar em uma área que ocorrem vários acidentes elétricos. Nessa cena, os alunos especulam várias possibilidades e o professor apenas acompanha o que está sendo dito por eles. Fato incomum pela caracterização inicial do professor, que remete a uma pessoa carrancuda, com ar de superioridade e, que possivelmente não aceitaria ouvir a opinião daqueles com menor conhecimento do que ele.

Também nessa cena, o professor não dá uma resposta pronta aos seus alunos sobre o que de fato faz com que a cidade seja propensa a descargas elétricas, 
podendo ser entendido que o professor demonstra que não necessariamente ele tem todas as respostas ou promove uma espécie de "ensino por investigação".

Essa metodologia de Sr. Rzykruski, possibilita aos estudantes que eles levantem hipóteses sobre determinado assunto e, que aos poucos vão buscando novas informações a respeito do problema encontrado sob a supervisão do professor, que possibilita que o estudante encontre respostas satisfatórias e corretas sobre o problema inicial.

O experimento de Victor talvez não teria sido o mesmo se não fosse a presença e a importância Sr. Rzykruski para Victor. Mesmo quando o menino tenta jogar beisebol - a pedido de seu pai - ele lembra das aulas do professor e, das falas incentivando e explicando que uma pesquisa exige paciência e foco ao pesquisador.

Ainda, após a morte de Sparky é na aula de Sr. Rzykruski que Victor tem uma luz de como voltar a viver feliz, afinal o menino tinha se isolado mais ainda do mundo e não conseguia manter sua atenção em nenhuma de suas atividades diárias. Ao ver um experimento realizado em sala de aula pelo professor, Victor decide utilizar alguns conceitos sobre eletricidade aprendidos e incorporar em sua pesquisa, fazendo um experimento complexo que teve como resultado a volta da vida de Sparky.

É importante destacar que o professor não foi o responsável pelo experimento de Victor, ele apenas deu subsídios necessários, como conhecimento para que o menino pudesse pensar em algo para trazer seu amigo de volta.

O professor levanta também a discussão sobre a evolução da Ciência, mesmo que de forma reduzida. Durante a reunião com o prefeito e os pais, o professor tem a audácia de enfrentar os pais que o atacam, por não compreenderem como a Ciência funciona. Essa revolta dos pais está relacionada com a forma como eles entendem que a Ciência funciona. Na cena, a percepção que os pais passam é que a Ciência é neutra e absoluta, dona de uma verdade incontestável. E, os pais não parecem compreender o processo evolutivo da Ciência e as implicações e as mudanças que ocorrem na sociedade. Isso é perceptível quando um dos pais levanta a questão que o livro utilizado pelo professor não trata Plutão mais como um planeta. Esse pai chega a dizer, que isso demonstra que Plutão //não é mais bom o suficiente para ser planeta, demonstrando total desconhecimento de como acontece uma pesquisa científica e os indícios que fizeram com que Plutão deixasse de ser um planeta.

Sr. Rzykruski chama os pais de ignorantes e desinformados e, levanta um ponto importante no seu discurso de que para muitos, a //Ciência é magia e bruxaria. Essa imagem de Ciência ainda é comumente veiculada e as pessoas se apegam em crendices e, ainda, que a Ciência é feita a partir de descobrimentos, as pesquisas acontecem por meio de mágica e de forma instantânea e com invenções utilitárias, que necessariamente melhorem a vida das pessoas.

Esse discurso do professor de desabafo soa como grosseiro e, por isso, ele é 
para que ela tenha maior desenvolvimento e, posteriormente possa a vir influenciar a vida das pessoas.

A cena na qual o professor discursa para os pais, traz vários aspectos a serem discutidos em sala de aula com os estudantes, pois ele levanta questões sobre a evolução científica, podendo ser realizada uma discussão a respeito de como o conhecimento científico é construído e, de qual forma ele é atualizado. Ainda, pode ser feita uma separação entre a magia e a Ciência, trazendo as principais diferenças e possibilitando uma reflexão dos motivos que levam algumas pessoas a não perceberem esse distanciamento.

Pode-se discutir os preceitos sobre a neutralidade da Ciência e os fatores que influenciam na pesquisa científica, possibilitando uma melhor compreensão dos estudantes a respeito de como acontece uma pesquisa científica e, quais as implicações da mesma. Além disso, é plausível uma comparação entre as cenas fílmicas com o conhecimento científico aceito tanto no ambiente escolar quanto na academia.

O professor não tem a chance de se despedir dos alunos e Victor procura-o enquanto ele está guardando suas coisas em seu carro. Victor se mostra muito desapontado por não ser avaliado pelo professor na Feira de Ciências, isso demonstra outra característica de Victor, de acreditar que ele pode ser o melhor mesmo sendo avaliado por alguém que tenha conhecimento suficiente e, superior ao dele sobre determinado assunto.

Ainda nessa conversa, o professor diz a Victor que de onde ele vem todos entendem de Ciência e que inclusive seu jardineiro já ganhou um Prêmio Nobel. Obviamente, o lugar de onde o professor vem não é mencionado e, aí cabe uma questão: será que as pessoas estão realmente preparadas para entender de Ciências? Será que um dia será possível que todos irão compreender o que é e como a Ciência funciona?

Nessa conversa, o professor incita que Victor seja um cientista, pois o menino sempre está cheio de perguntas e é isso que um cientista precisa ter. Victor recua, pois acredita que os cientistas não são bem vistos pela sociedade. De fato, a imagem veiculada de cientistas é sempre remetida a pessoas que abandonam suas famílias, que são isoladas e que vivem em função de suas pesquisas. Muitas vezes, as pessoas expressam rejeição com os cientistas, sem ao menos conhecer de fato o seu trabalho e como ele acontece.

Um dos principais diferenciais da pesquisa de Victor em Frankenweenie é compreendida na conversa de Victor com Sr. Rzykruski, na qual o menino busca compreender os motivos que seu experimento na primeira vez com Sparky deu certo e depois com o peixe de Edgar não. O professor explica que umas das variáveis é o amor ao experimento. De certa forma, foi o amor de Victor que o fez agir para devolver a vida de Sparky e o fez correr os riscos necessários para isso mesmo que talvez não tenha tido consciência disso por ser apenas uma criança. Esse é o diferencial das outras obras inspiradas em Frankenstein, é que fazem com que o filme seja menos gótico e mais emotivo do que os demais. 
Nesse mesmo sentido, o professor complementa afirmando que fazer Ciência não depende apenas da mente, como também do coração. Essa fala demonstra que o pesquisador precisa estar de fato envolvido com sua pesquisa, precisa ser apaixonado por Ciência e não a fazer por simples reconhecimento ou esperando algo a mais.

E por fim, a última fala do professor para Victor //Ciência não é boa nem má, Victor. Mas pode ser usada das duas formas. É por isso que você sempre deve ter cuidado. Essa fala funciona para reflexão de como a Ciência tem sido mostrado, com quais princípios e de que forma ela tem sido realizada. E mais do que isso, a Ciência desenvolve técnicas e pesquisas e, dependem do homem a forma como ela será usada. Apenas do homem. Por isso, se a Ciência é vista como algo prejudicial ao homem, a sociedade e/ou meio ambiente é por causa do seu uso irresponsável e não propriamente dito por culpa da pesquisa científica.

A cena na qual Victor traz Sparky de volta a vida chama a atenção, pois ele utiliza os mais diferentes equipamentos e mais diferentes conexões para conseguir produzir um sistema capaz de capturar os raios da tempestade e, o transformarem em descargas elétricas que atinjam com a devida potência e, pelo tempo necessário o corpo de Sparky. Durante o experimento, Victor realiza várias anotações e até sua vestimenta está de acordo com o importante experimento que ele está realizando, pois agora ele está usando jaleco, luvas e óculos de proteção.

Essa cena mostra várias adaptações realizadas pelo menino, que foram projetadas em poucas horas. Logo após o seu experimento, Victor acredita que ele não funcionou e o menino fica desolado, até que Sparky começa a se movimentar e a emoção toma conta da cena. Victor fica extremamente feliz por ter conseguido reviver seu melhor amigo e, ainda, conseguiu realizar seu experimento com sucesso. Ele profere uma frase também muito presente nos filmes com a temática Frankenstein "Você está vivo!", como uma forma de demonstrar que também está surpreso com o que acaba de conseguir fazer.

Outro aspecto relativo ao filme, é que Victor gostaria de manter seu experimento em segredo, que julgamos ser por três motivos. Um deles é que ele sabia que poderia ganhar o prêmio na Feira de Ciência com o seu experimento, o segundo é devido ao seu afeto e amor incondicional ao seu experimento e, por último por ter medo da reação das pessoas quando soubessem o seu ato.

Mesmo após a realização do experimento, Victor não se caracteriza como uma criança ambiciosa e que busca a glória eterna a partir do seu experimento. Entretanto, ele quer ganhar a Feira de Ciências para ser consagrado com o melhor aluno de Ciências de sua classe e, o mais importante, ele quer fazer isso sozinho, recusando a ajuda de Edgar e se isolando mais durante esse processo.

O segundo motivo é que Victor realizou a experiência por amor ao seu animal e por se sentir sozinho sem ele. Talvez passasse na sua cabeça que deveria manter Sparky escondido como uma forma de proteção, para não correr o risco de o perder novamente, já que a primeira perda foi significativa e marcante para ele. 
com o passar das horas ele tomou consciência de seu ato. Inclusive seu pai reprova sua atitude quando descobre que Sparky está vivo. Entretanto, a conversa que promete ter com o filho sobre essa atitude, durante o filme nunca chega a ser consumada, devido a sequência de fatos que vão acontecendo na mesma noite e, que trazem maior dramaticidade a trama.

Nessas cenas, é possível perceber que a motivação do experimento de Victor foi algo pessoal. Essa imagem de que a Ciência e os cientistas realizam experimentos para fins próprios, é amplamente divulgada pelo cinema e pela mídia em geral, reforçando preconceitos que auxiliam na formação da imagem de uma Ciência ingênua, completamente afastada do que supõe ser o trabalho e da construção do conhecimento científico.

Por isso, é essencial em sala de aula uma discussão sobre as motivações da pesquisa científica e, de quais formas ela acontecem, destacando as diferentes interferências possíveis sob ela. Também pode-se considerar que os estudantes realizem uma pesquisa científica, a fim de que conheçam algumas variáveis possíveis durante esse processo.

Quando o experimento de Victor é descoberto por Edgar, esse utiliza como arma contra Victor, fazendo chantagem para ser o seu parceiro durante a Feira de Ciências. Edgar é um menino corcunda e que quer muito ser o companheiro de Victor na Feira de Ciências, ele pode ser facilmente comparado com o corcunda Ygor, ajudante de Frankenstein em algumas adaptações para o cinema.

Para Victor, Sparky não é apenas um experimento, ele é seu amigo e cachorro, por isso decide repetir o procedimento com um peixe trazido por Edgar. Algo extraordinário acontece, o peixe fica invisível e isso faz com que Edgar saia contando a novidade para os colegas de classe. Para Führ (2016a), a criação de um peixe invisível pode estar referenciada à obra de suspense e terror $\mathrm{O}$ Homem Invisível (1933) dirigido por James Whale, como uma forma de homenagem de Tim Burton.

Edgar age dessa forma por acreditar que é superior aos demais por estar fazendo dupla com Victor. Na realidade, Victor não está fazendo dupla com ele, Victor faz sua vontade e mostra como trouxe Sparky de volta a vida, mas continua sem estabelecer laços com Edgar.

Edgar ao contar aos colegas sobre o experimento com o peixe causa inveja nos meninos, que prontamente percebem que precisam elaborar um projeto melhor do que aquele para a Feira de Ciências.

Toshiaki e Bob formam uma dupla, a relação dos dois se dá da seguinte maneira: Toshiaki é o mais inteligente e formula os planos a serem realizados, enquanto Bob é a cobaia. Toshiaki decide testar e coletar dados de um foguete de garrafas nas costas de Bob. O plano não dá certo, enquanto Bob está machucado, Toshiaki continua com um ar de superioridade buscando algo que consiga superar o projeto de Victor e Edgar. 
Sparky está de volta. Na ânsia de serem melhores que Victor na Feira de Ciências, os meninos invadem o sótão de Victor copiam ideias e observam os equipamentos montados por ele.

Toshiaki e Nastro vão até o cemitério e desenterram seus animais de estimação mortos, enquanto Edgar captura um rato dentro de uma lata de lixo, Bob usa gomas de mascar e a Menina Esquisita usa um morcego capturado por seu gato.

Contudo, o experimento de nenhum deles dá certo e eles acabam recorrendo a Victor para os ajudar a solucionar os problemas causados a partir de criações bizarras.

Essas cenas do filme mostram um lado pouco divulgado da Ciência, o lado competitivo, a rivalidade e o plágio. Os meninos da classe de Victor se unem para descobrir os segredos de Victor, entretanto, na hora de reproduzirem os experimentos cada um deles fez por si, inclusive desfazendo as duplas feitas anteriormente, como Toshiaki e Bob. Como se pela Ciência e pelas pesquisas científicas valesse todo e qualquer tipo de atitude, seja de trapaça ou até mesmo de desfazer amizades, pela conquista de um prêmio ou até mesmo o reconhecimento.

Ao contrário de Sparky que manteve suas caracterizas psicológicas e físicas mesmo após reviver, as criaturas dos colegas de classe tornam-se verdadeiros monstros e com tamanhos desproporcionais. Uma forma de reflexão que o filme propicia é que essas criaturas foram revividas pelos motivos errados, que era principalmente superar o experimento de Victor. Enquanto o experimento de Victor estava muito mais relacionado ao carinho e ao amor que tinha pelo seu cachorro.

A criatura da Menina Esquisita se transforma em um gato morcego voador, que irá perseguir a todos na cidade. A criatura de Nassor, antes um hamster se torna uma múmia, que com um jogo de sombras aparenta ser um monstro enorme, mas mantém o seu tamanho original. Para Führ (2016a), a cena na qual Colossus (hamster) volta a viver é em referência ao filme A Múmia (1932), no qual Boris Karloff interpretava Imhotep, uma múmia que foi enterrado vivo por ter cometido um sacrilégio.

A pequena tartaruga Shelley de Toshiaki, se torna uma grande tartaruga que pisa em Colossus logo após sua criação. A criatura de Edgar se torna em um rato gigante que persegue a professora de educação física pela escola. E por fim, Bob cria mais do que uma criatura, ele cria várias delas que parecem pequenos monstrinhos, que ao comerem pipoca salgada explodem, pois Victor percebe que eles são sensíveis ao sal.

As criaturas dos colegas de classe de Victor causam verdadeiro caos na cidade, interrompendo o Dia Holandês. Sparky percebe que Persephone e Elsa estão em perigo e decidem segui-las até um moinho. Mas ele é acusado pelo sumiço de Elsa e por isso, todos os homens da cidade vão atrás dele com tochas nas mãos. sobrinha, de Sparky, de Persephone e de Victor. Assim como nos clássicos de 
Frankenstein, a criatura, nesse caso Sparky morre (de novo), sendo retirada do moinho depois de um tempo. A dor de Victor é inenarrável, o menino parece sofrer mais do que a última vez.

Mas desta vez Victor pode contar com seu pai, que consegue compreender a dor de seu filho e propõe que Victor tente novamente trazer Sparky a vida. Após a união de vários cabos nos motores dos veículos da cidade, finalmente eles conseguem trazer Sparky de volta a vida, para a felicidade de Victor e de toda a população que comemora, devido os feitos realizados por Sparky para salvar a todos que estavam no moinho.

Sparky termina o filme encostando o seu focinho no de Persephone, que é o grande amor do cachorro. Essa cena faz referência ao filme A noiva de Frankenstein (1935) também dirigido por James Whale. Pois no filme de Whale, a criatura fica feliz ao acreditar que finalmente encontrou uma companheira, assim como Sparky. As semelhanças são maiores ainda, pois os cabelos da noiva no segundo filme possuíam mechas brancas, que fazem parte do pelo de Persephone na animação Frankenweenie (FÜHR, 2016a).

E com Persephone há ainda mais uma intertextualidade, pois o nome da cachorro é na mitologia grega o nome da filha de Zeus e Démeter "[...] pela qual Hades, irmão de Zeus, se apaixona. Segundo a mitologia, Perséfone comeu grãos de romã que firmam sua união com Hades, o que a tornou rainha do Reino dos Mortos" (FÜHR, 2016a, p. 10).

Esse filme traz a Ciência basicamente como experimental, afinal o enredo do filme gira em torno de um experimento realizado por Victor para trazer seu cachorro de volta a vida. Em várias outras cenas, o experimento faz parte do filme, como uma forma de constatação e comprovação científica, como se toda e qualquer pesquisa científica precisasse necessariamente de algum experimento para ter seu devido reconhecimento.

\section{CONSIDERAÇÕES FINAIS}

O filme Frankenweenie (2012) traz muito mais que aspectos sombrios e a temática de Frankenstein. Ele é um filme que faz homenagens significativas e que traz como enredo a história de um garoto que tem grande dificuldade para se despedir de seu melhor amigo e que, por ter aptidões científicas consegue reviver seu animal de estimação, demonstrando total afeto e carinho pelo animal.

Com este filme é possível trazer importantes discussões a respeito da imagem de Ciência e cientistas presentes no contexto do meio fílmico, que podem ser amplamente trabalhados em sala de aula, de diferentes formas e de forma interdisciplinar. Podendo ser abordados aspectos relativos as discussões sobre o andamento da pesquisa científica, a competição e/ou cooperação entre pesquisadores, a ética e os limites e implicações da Ciência.

O personagem principal do filme, Victor pode ser o enfoque em uma atividade escolar, podendo discutir com os estudantes as motivações do menino durante o experimento, sua relação com o conhecimento científico, suas habilidades e ainda 
a forma como sua pesquisa se desenvolve ao decorrer do filme. Pelo fator de Victor ser uma criança, seu personagem pode ser usado como um elemento motivador dos estudantes, que muitas vezes não se imaginam como cientistas e se consideram imaturos e jovens demais para ingressarem em pesquisas e na produção de conhecimento científico.

Ainda, podem ser abordados temas ou conteúdos programáticos durante o enredo do filme, como o método científico nas aulas de ciências, a questão da eletricidade nas aulas de física, vidrarias, equipamentos e a segurança do laboratório nas aulas de química, a composição corporal dos animais na biologia, entre outras disciplinas, que podem incorporar e desenvolver diferentes atividades a partir do filme.

O filme Frankenweenie (2012) apresenta diferentes potencialidades no Ensino de Ciências, a escolha da atividade a ser realizada depende da intencionalidade e dos objetivos que o professor tem com a exibição do filme no ambiente escolar. 


\title{
"Frankenweenie": a look at the half film and the science teaching
}

\begin{abstract}
The cinema is part of the daily life of the students, either by the habit of going to the theater or watching movies at home. In the school environment cinema has different potentialities, and can be an instrument for discussion, research or for the development of activities related to the concepts treated in the classroom. Therefore, it is necessary to look at the film in order to understand the aesthetic dimension, the ideology and the sociocultural values present in the filmic environment. In this perspective, the animated film "Frankenweenie", launched in the year 2012, was watched, described and analyzed, addressing broad and detailed aspects of the film, which can be discussed during Science classes, presenting a description of the image of Science and Scientists present in this film in order to instruct or mentor teachers while working with movies in the classroom. From this, we observe that the represented scientist is Victor, a boy who was born with abilities focused on Science, because he has much intellectual ability in the discipline of Sciences and for the handling of different equipment. When you see your dog and best friend die, decide to use the knowledge learned in science classes, to revive your animal. The film brings different aspects of scientific research, such as competition and the variables involved in the process. However, it presents science basically as experimental, because throughout the plot, the research of Victor and his colleagues is always related to experimental proofs. KEYWORDS: Science teaching. Cine. Science Image.
\end{abstract}




\section{REFERÊNCIAS}

ANDRADE, E. C. P. O Professor de Ciências e o Cinema: Possibilidades de discussão. Revista Ciência \& Ensino. v. 1, n. 9, p. 4-6, dez. 2000.

DUARTE, R. Cinema e educação. Belo Horizonte: Autêntica, 2002.

DUARTE, R.; ALEGRIA, J. Formação Estética Audiovisual: um outro olhar para o cinema a partir da educação. Revista Educação \& Realidade, v. 33, n. 1, p. 59-80, jan/jun. 2008.

FABRIS, E. H. Cinema e Educação: um caminho metodológico. Revista Educação e Realidade, v.33, n. 1, p. 117-134, jan./jun. 2008.

FÜHR, F. Frankenweenie: adaptação fílmica e intertextualidade. Anais XVII Congresso de Ciências da Comunicação na Região Sul, Curitiba-PR, 2016a, p. 1-14.

FÜHR, F. Frankenweenie: entre luz e sombras. Revista Temática, v. 12, n. 5, p. 97113, mai. 2016.

KÜCHLER, A. Cachorro "Frankenstein" de nova animação de Tim Burton existiu de verdade. Disponível em:

<http://www1.folha.uol.com.br/serafina/2012/11/1174648-cachorro-

frankenstein-de-nova-animacao-de-tim-burton-existiu-de-verdade.shtml> Acesso em: mar. 2017.

MAYO, M. F. In: WOODS, Paul A. O Estranho Mundo de Tim Burton. Texto editores: São Paulo, 2011.

OLIVEIRA, B. J. Cinema e Imaginário científico. Revista História, Ciências e Saúde. v. 13, supl. p. 133-150, 2006.

ROURE, G. Q.; SÁ, A. C. R. M. Vicente e Frankenweenie: a infância no cinema "expressionista" de Tim Burton. Revista Polyphonía, v. 25, n. 2, p. 535-556, jul/dez. 2014

SILVA, R. C. Trajetória e natureza das políticas audiovisuais no Brasil. In: VI ENECULT - Encontro de estudos multidisciplinares em cultura, 2010. Salvador. Anais VI ENECULT. Salvador: Universidade Federal da Bahia, 2010. Disponível em: <http://www.cult.ufba.br/wordpress/24859.pdf> acesso: mai. 2017.

VANOYE, F. Ensaio sobre a análise fílmica, 5 ed. Campinas, SP: Editora Papirus, 2008. 
Recebido: 30 jul. 2017

Aprovado: 03 dez. 2017

DOI: $10.3895 /$ actio.v2n3.6861

Como citar:

SILVA, R. S.; CUNHA, M. B. "Frankenweenie": um olhar para o meio fílmico e o ensino de ciências. ACTIO Curitiba, v. 2, n. 3, p. 208-228, out./dez. 2017. Disponível em: <https://periodicos.utfpr.edu.br/actio>. Acesso em: $X X X$

Correspondência:

Kathya Rogéria da Silva

Rua Marechal Floriano, 3922, 85811-150, Cascavel, Paraná, Brasil.

Direito autoral: Este artigo está licenciado sob os termos da Licença Creative Commons-Atribuição 4.0

Internacional.

(c) (1) 